\title{
EFICIÊNCIA E VIABILIDADE ECONÔMICA DA APLICAÇÃO DE FUNGICIDAS NO CONTROLE DA FERRUGEM ASIÁTICA DA SOJA EM CAMPO GRANDE, MS
}

\author{
R. Gasparetto ${ }^{1}$, C.D. Fernandes ${ }^{1}$, C.E. Marchi ${ }^{2}$, M. de F. Borges ${ }^{3}$ \\ ${ }^{1}$ Universidade para o Desenvolvimento do Estado e da Região do Pantanal, CP 2153, CEP 79003-010, Campo \\ Grande, MS, Brasil.
}

\section{RESUMO}

\begin{abstract}
Objetivou-se avaliar a eficiência e a viabilidade econômica da aplicação de fungicidas no controle da ferrugem asiática da soja, Phakopsora packyrhizi, em Campo Grande, MS. O ensaio foi conduzido em na safra 2007-2008. Foram avaliados os fungicidas (g i.a./ha): picoxistrobina + ciproconazole $(40+16,50+20$ e $60+24)+$ nimbus $0,25 \%(\mathrm{v} / \mathrm{v})$, piraclostrobina + epoxiconazole $(66,5+25)$; azoxistrobina + ciproconazole $(60+24)+$ nimbus $0,25 \%(\mathrm{v} / \mathrm{v})$; trifloxistrobina + tebuconazole $(50$ + 100) + auero 0,13\% (v/v) e trifloxistrobina + ciproconazole $(56,25+24)+$ aureo 0,13\% (v/v). Três aplicações foram realizadas, quinzenalmente, a partir do estádio fenológico R2. Foram realizadas 10 avaliações da severidade da doença (terços inferior e superior da planta) e três da desfolha (a partir do estádio R7), com intervalos de sete dias. Após plotagem das curvas de progresso (CP), foram calculadas as áreas abaixo das $\mathrm{CP}$ para a severidade da doença (AACPD) e desfolha (AACPDes). Ao final do ensaio, avaliou-se o rendimento de grãos (Rend - kg/ha), a massa de 1.000 grãos (MMG - g) e a viabilidade econômica do controle da doença. O clima durante a condução do ensaio foi favorável ao desenvolvimento da ferrugem asiática, constatando-se relação positiva entre a precipitação e a severidade da doença. Todos os fungicidas apresentaram valores de AACPD inferiores ao da testemunha, com destaque para picoxistrobina + ciproconazole (maior dose). Esse tratamento também apresentou o menor índice de AACPDes. Os fungicidas apresentaram índices semelhantes de Rend, embora superiores à testemunha. Quanto a MMG, maior índice foi atribuído a azoxistrobina + ciproconazole. A mistura trifloxistrobina + tebuconazole apresentou a menor eficiência de controle da ferrugem asiática. Com base na severidade da doença, rendimento de grãos e nos benefícios econômico gerados pela aplicação de fungicidas, identificou-se os fungicidas picoxistrobina + ciproconazole $(60+24)$, azoxistrobina + ciproconazole e trifloxistrobina + ciproconazole como os mais promissores para o controle de P. packyrhizi.
\end{abstract}

PALAVRAS-CHAVE: Phakopsora pachyrhizi, Glycine max, controle químico.

\section{ABSTRACT}

EFFICIENCY AND ECONOMIC VIABILITY OF APPLICATION OF FUNGICIDES IN THE CONTROL OF ASIATIC RUST OF SOYBEANS IN CAMPO GRANDE, MS, BRAZIL. The present study evaluated the efficiency and the economic viability of the application of fungicides to control Asian soybean rust, Phakopsora packyrhizi, in Campo Grande, state of Mato Grosso do Sul, Brazil. The assay was carried in the 2007-2008 harvest. The following fungicides were evaluated (g a.i./ ha): picoxystrobin + cyproconazol $(40+16,50+20$ and $60+24)+$ nimbus $0.25 \%$ (v/v); pyraclostrobin + epoxiconazol $(66.5+25)$; azoxystrobin + cyproconazol $(60+24)+$ nimbus $0.25 \%(\mathrm{v} / \mathrm{v})$; trifloxystrobin + tebuconazol $(50+100)+$ auero $0.13 \%(\mathrm{v} / \mathrm{v})$ and trifloxystrobin + cyproconazol $(56.25+24)+$ aureo $0.13 \%(\mathrm{v} / \mathrm{v})$. The fungicide treatments started from the phenologic stage R2. Three applications were realized, 15 days apart. The disease severity (upper and lower part of the plant) was quantified weekly, totaling 10 evaluations. In addition, at the R7 stage, the defoliation was evaluated every seven days. The curves of progress $(\mathrm{CP})$ were plotted and calculated the areas under the CP for the disease severity (AACPD) and defoliation (AACPDes). At the end of the assay, the grain yield (Rend - kg/ha), the mass of 1,000 grains (MMG - g) and the economic viability of the disease control were evaluated. The climate during the conduction of the experiment was favorable to the development of Asian soybean rust. There was a positive relationship between rainfall and severity of the disease. All fungicides showed AACPD below the control, especially picoxystrobin + cyproconazol (higher fungicide dose). This treatment also showed the lowest rate

${ }^{2}$ Embrapa Gado de Corte, Laboratório de Fitopatologia, Campo Grande, MS, Brasil.

${ }^{3}$ Laboratório Nacional Agropecuário em São Paulo (Lanagro-SP), Jundiaí, SP, Brasil. 
of AACPDes. The fungicides presented similar rates of Rend, although higher than the control treatment. In relation to MMG, the highest index was attributed to azoxystrobin + cyproconazol. The mixture trifloxystrobin + tebuconazol showed the lowest efficiency for the control of Asian soybean rust. Based on the severity of the disease, grain yield and the economic benefits generated by the application of fungicides, picoxystrobin + cyproconazol $(60+24)$, azoxystrobin + cyproconazol and trifloxystrobin + cyproconazol were identified as the most promising for the control of P. packyrhizi.

KEY WORDS: Phakopsora pachyrhizi, Glycine max, chemical control.

\section{INTRODUÇÃO}

A cultura da soja [Glycine max (L.) Merrill] constitui forte componente da economia brasileira, com produção de grãos estimada em 57,6 milhões de toneladas para 2009 (IвGE, 2009). O potencial produtivo da soja é afetado por várias doenças, entre os quais se destaca a ferrugem asiática. $\mathrm{Na}$ safra 2003-2004, com a ocorrência da doença, o Brasil deixou de produzir 4,5 milhões de toneladas de grãos (BARRos et al., 2008).

Causada pelo fungo Phakopsora pachyrhizi $(\mathrm{H}$. Sydow \& Sydow), a ferrugem asiática representa o principal problema sanitário da cultura no Brasil (YORINORI, 2007). A primeira constatação de $P$. pachyrhizi no país foi na safra 2000-2001, na região oeste do Paraná (YoRINORI et al., 2002) e, desde então, alcançou todas as regiões brasileiras.

Em condições favoráveis, as perdas na produtividade podem variar de 10 a 80\% (Mori; COSTAMILAN, 2004). Segundo o BRASIL (2008), as perdas em grãos na safra 2007-2008 corresponderam a 418,5 mil toneladas, e o custo ferrugem, compreendido como a soma do prejuízo de grãos, custo de controle e arrecadação, atingiu US\$2,38 bilhões.

Os sintomas iniciais da doença são pequenas pústulas foliares, de coloração castanha a marromescura (SINCLAIR; HARTMAN, 1999). Na face abaxial da folha observam-se as urédias que, ao se romperem, liberam os urediniósporos. As lesões apresentam formato angular, atingindo 2 a $5 \mathrm{~mm}$ de diâmetro. A doença evoluirapidamentecausando amarelecimento equeda prematura das folhas, o que reduz a produção de fotoassimilados e prejudica o enchimento dos grãos. Quanto mais cedo ocorrer a desfolha, menor será o tamanho dos grãos e, consequentemente, maior a perda de rendimento e qualidade (GoDor et al., 2003).

Vários métodos devem ser integrados para o manejo adequado da ferrugem asiática, tais como destruição de plantas voluntárias, vazio sanitário, uso de cultivares precoces, monitoramento da lavoura e controle químico (BRASIL, 2008). A aplicação preventiva de fungicidas tem se destacado como estratégia mais eficaz no manejo de $P$. pachyrhizi (AzEVEDO, 2001). A aplicação de fungicidas também é considerada a medida de controle eficaz quando a doença já se encontra instalada no campo (SOARES et al., 2004).

Neste trabalho objetivou-se avaliar a eficiência da aplicação de fungicidas no controle da ferrugem asiática da soja, para as condições de Campo Grande, MS, bem como analisar a viabilidade econômica do controle químico da doença.

\section{MATERIAL E MÉTODOS}

$\mathrm{O}$ experimento foi conduzido em área experimental da Embrapa Gado de Corte (20 $27^{\prime}$ S; 54 $37^{\prime}$ W; 530 m de altitude), Campo Grande, MS, na safra 2007-2008, sobre solo classificado como Latossolo Vermelho distroférrico típico, textura argila arenosa. Dados climáticos diários foram obtidos junto à Estação Climatológica da Embrapa Gado de Corte, especificamente a temperatura média (Tmed, em ${ }^{\circ} \mathrm{C}$ ), precipitação (Prec, em $\mathrm{mm}$ ) e umidade relativa do ar (UR, em \%).

Utilizou-se a cultivar de soja transgênica BRS 256 RR, de ciclo médio, a qual foi semeada em 20/11/2007 em sistema de plantio direto, na profundidade de $2-5 \mathrm{~cm}$. Com o auxílio da semeadora Semeato SHM 15/17, foram distribuídas 22 sementes/m linear (linhas espaçadas de $0,45 \mathrm{~m}$ ) sobre a palhada de $\mathrm{Bra}$ chiaria brizantha cv. Xaraés dessecada com glifosato. A adubação de plantio consistiu em $400 \mathrm{~kg} / \mathrm{ha}$ da formulação 05-20-15. Durante a condução do ensaio, os insetos-pragas incidentes foram controlados conforme indicações para a cultura.

O experimento foi delineado em blocos ao acaso (DBC), com quatro repetições. A área total da parcela experimental foi de $30 \mathrm{~m}^{2}(3 \times 10 \mathrm{~m})$ e a área útil de $8,1 \mathrm{~m}^{2}(1,35 \times 6 \mathrm{~m})$. Nas parcelas foram dispostos os tratamentos: 1- testemunha; 2- picoxistrobina + ciproconazole $(40+16$ g i.a./ha $)+$ nimbus $0,25 \%$ v/v; 3- picoxistrobina + ciproconazole $(50+20 \mathrm{~g}$ i.a./ha) + nimbus $0,25 \% \mathrm{v} / \mathrm{v}$; 4 - picoxistrobina + ciproconazole $(60+24$ g i.a./ha $)+$ nimbus $0,25 \%$ v/v; 5- piraclostrobina + epoxiconazole $(66,5+25$ g i.a./ha); 6- azoxistrobina + ciproconazole $(60+24$ gi.a./ha) + nimbus $0,25 \% \mathrm{v} / \mathrm{v}$; 7 - trifloxistrobina + tebuconazole $(50+100$ g i.a./ ha) + auero $0,13 \% \mathrm{v} / \mathrm{v}$; 8- trifloxistrobina + ciproconazole $(56,25+24$ g i.a./ ha) + aureo $0,13 \% \mathrm{v} / \mathrm{v}$. 
As aplicações de fungicidas foram feitas com pulverizador costal pressurizado por $\mathrm{CO}_{2}$, com pressão ajustada para $2,81 \mathrm{kgf} / \mathrm{cm}^{2}$ (40 psi ou libras / $\mathrm{pol}^{2}$ ), aferida no manômetro de saída para a barra de pulverização de $3 \mathrm{~m}$ de comprimento. As pontas de pulverização tipo leque (110-02) foram calibradas para pulverizar $200 \mathrm{~L} /$ ha de calda. Três aplicações foram realizadas durante o experimento, nos estádios fenológicos R2 (23/1/2008), R4 (7/2/2008) e R5 (21/2/2008).

Ao longo do desenvolvimento da cultura monitorou-se a severidade da ferrugem asiática, amostrando-se 10 folhas do terço inferior e 10 folhas do terço superior, as quais foram coletadas aleatoriamente na área útil da parcela. Para a quantificação da doença utilizou-se a escala diagramática proposta por Godoy etal. (2006), ilustrada na Figura 1. Na ausência da ferrugem asiática foi atribuída a nota 0 (zero). Realizou-se a primeira quantificação da doença em $23 / 1 / 2208$ e, a partir de então, quantificou-se a ferrugem semanalmente até o estádio $R 8$, totalizando 10 avaliações. A pós coleta dos dados, foram plotadas as curvas de progresso da doença (CPD) nas folhas inferiores ou superiores, bem como calculadas as respectivas áreas abaixo da CPD (AACPD), usandose a seguinte fórmula (WHITE et al., 2001):

$$
A A C P D=\sum_{i}^{n-1}\left(\frac{y_{i}+y_{i+1}}{2}\right)\left(t_{i+1}-t_{i}\right)
$$

onde yi e yi+1 são correspondem à severidade da ferrugem nos tempos ti e ti+1, respectivamente e n é o número de avaliações realizadas no período.

A desfolha foi avaliada semanalmente a partir do estádio fenológico R7, totalizando três avaliações. Por meio deexame visual, estimou-se a porcentagem de desfolha para cada tratamento, conforme REIS et al. (2007). Com esses dados plotou-se as curvas de progresso da desfolha (CPDes) e calculou-se as áreas abaixo das CPDes (AACPDes), de forma similar à utilizada para a severidade da doença. Ao final do ciclo da cultura, realizou-se a colheita manual das plantas nas três linhas centrais da área útil das parcelas. Essas plantas foram trilhadas manualmente e os grãos acondicionados em sacos de papel. Em seguida, foram determinados o rendimento de grãos (Rend, em kg/ha) e a massa de mil grãos (MMG, em g), os quais foram corrigidos pela umidade dos grãos, ajustado a $13 \%$ em base úmida.

As análises estatísticas foram realizadas com o auxílio do programa SAS (2003), empregando-se o teste de Duncan a 5\% de probabilidade para as comparações múltiplas entre as médias.

A margem líquida, constituída pelos benefícios adicionais do controle da ferrugem asiática, foi calculada utilizando-se a técnica de orçamentação parcial (Hoffmann et al., 1984). Em adição, calcularam-se o lucro líquido e o ganho (\%) em receita, proporcionados pela aplicação dos fungicidas.

\section{RESULTADOS E DISCUSSÃO}

Os primeiros sintomas de $P$. pachyrhizi na soja foram detectados após a primeira aplicação de fungicidas, especificamente em 30/1/2008 (Fig. 2). $\mathrm{O}$ desenvolvimento da doença iniciou-se no terço inferior das plantas, devido às melhores condições para o fungo. O microclima gerado na parte baixeira da planta, caracterizado pela maior umidade, baixa penetração de luz solar e temperaturas mais amenas, favorecem a infecção do patógeno, desencadeando o processo de doença (BRASIL, 2008). A aplicação dos fungicidas retardou o aparecimento dos primeiros sintomas de ferrugem asiática em uma semana. No início do mês de fevereiro notou-se o progresso da doença em todos os tratamentos (Fig. 2).

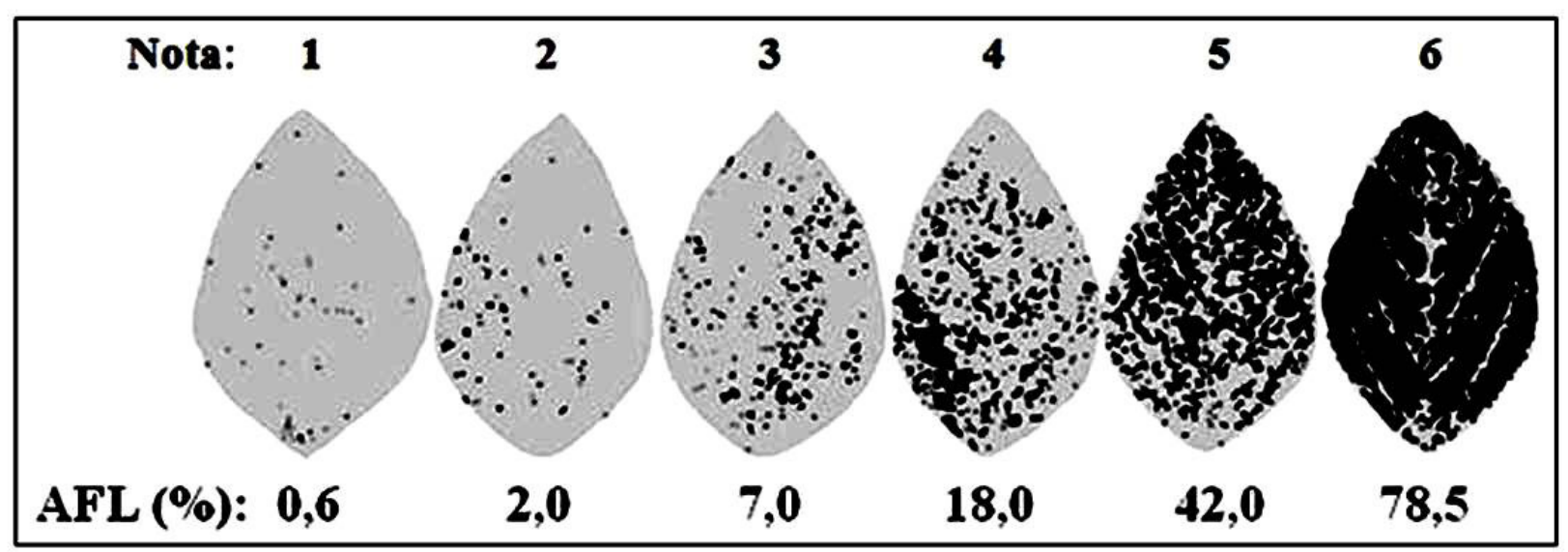

Fig. 1 - Escala diagramática para a avaliação da severidade da ferrugem asiática da soja, causada por Phakopsora packyrhizi, proposta por Godor et al. (2006). AFL: área foliar lesionada. 

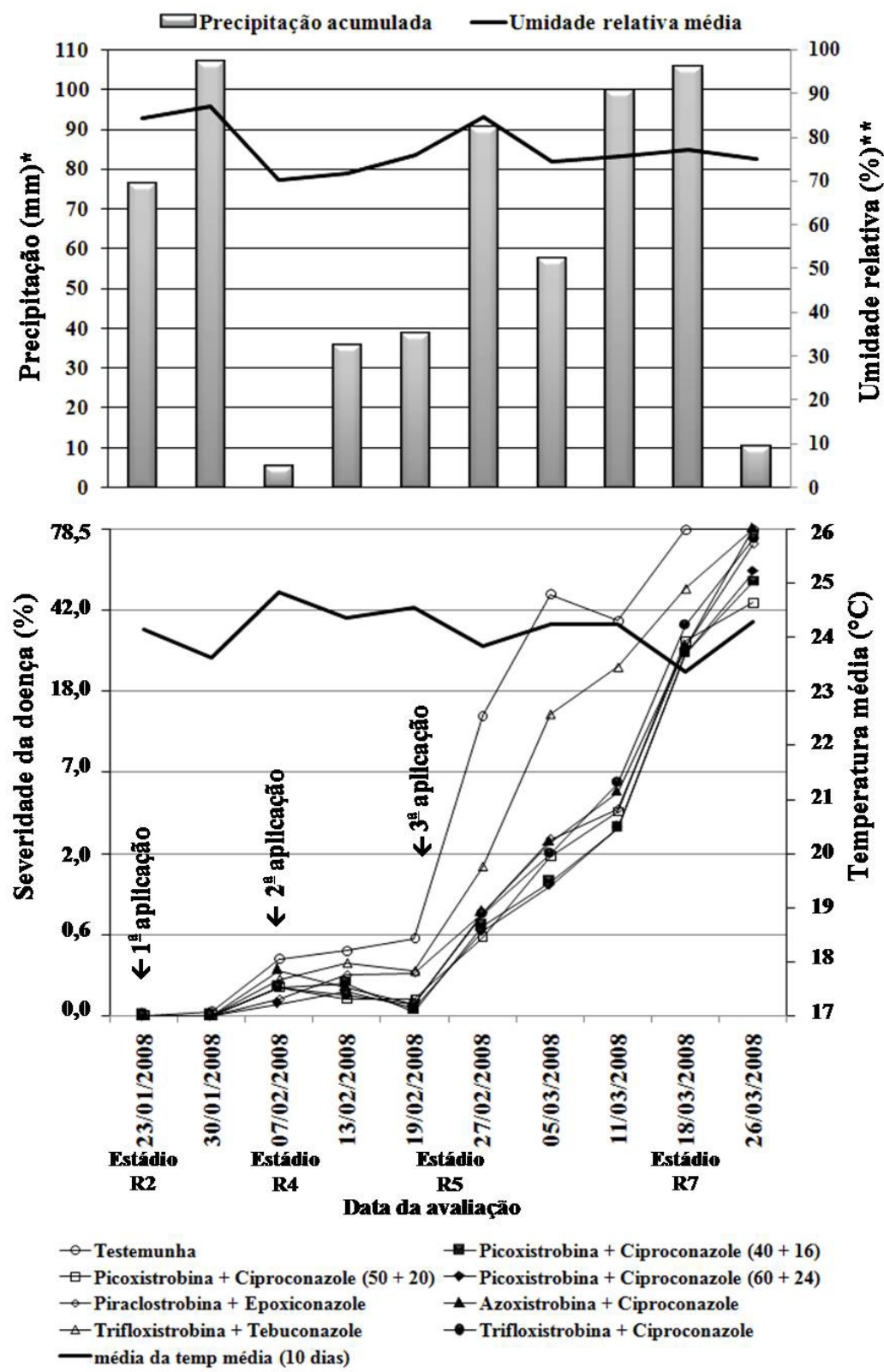

Fig. 2 - Curva de progresso da severidade da ferrugem asiática, Phakopsora pachyrhizi, no terço inferior de plantas de soja cultivar BRS 256 RR submetidas ou não às aplicações de fungicidas e a relação com as condições climáticas. Campo Grande, MS, 2007-2008. Acúmulo $\left(^{*}\right)$ e média $\left({ }^{* *}\right)$ de 10 dias priori a data da avaliação da doença. Valores entre parênteses na legenda correspondem à dose do produto (g i.a./ha).

Entre 7/2 e 19/2/2008 não houve aumento expressivo da severidade da doença no terço inferior das plantas não tratadas (Fig. 2). Deste ponto em diante, em geral, constataram-se aumentos crescentes da severidade de $P$. pachyrhizi, sobretudo no tratamento testemunha, refletindo a alta capacidade de dispersão e agressividade do patógeno (Furlan, 2005). No início do mês de março, plantas não tratadas já apresentavam $42,0 \%$ de severidade da ferrugem asiática, enquanto nas plantas tratadas os índices de ferrugem variaram de 1,4 (picoxistrobina + ciproconazole - $60+24$ g i.a/ha) a $14,9 \%$ (trifloxistrobina + tebuconazole) de severidade(Fig.
2). A partir de 11/03/08, observou-se mudança no padrão das curvas de progresso da doença em plantas submetidas à aplicação de fungicidas, exceção feita ao fungicida trifloxistrobina + tebuconazole. Nestas plantas, osíndices de severidade da ferrugem asiática aumentaram rapidamente, passando de 3,6 (picoxistrobina + ciproconazole $-40+16$ g i.a/ha) a 6,4\% (trifloxistrobina + ciproconazole) para 29,3 (picoxistrobina + ciproconazole - doses menor e maior) a 37,4\% (trifloxistrobina + ciproconazole), possivelmente devido à redução término da ação fungicida e/ou da precipitação acumulada no período (Fig. 2). 

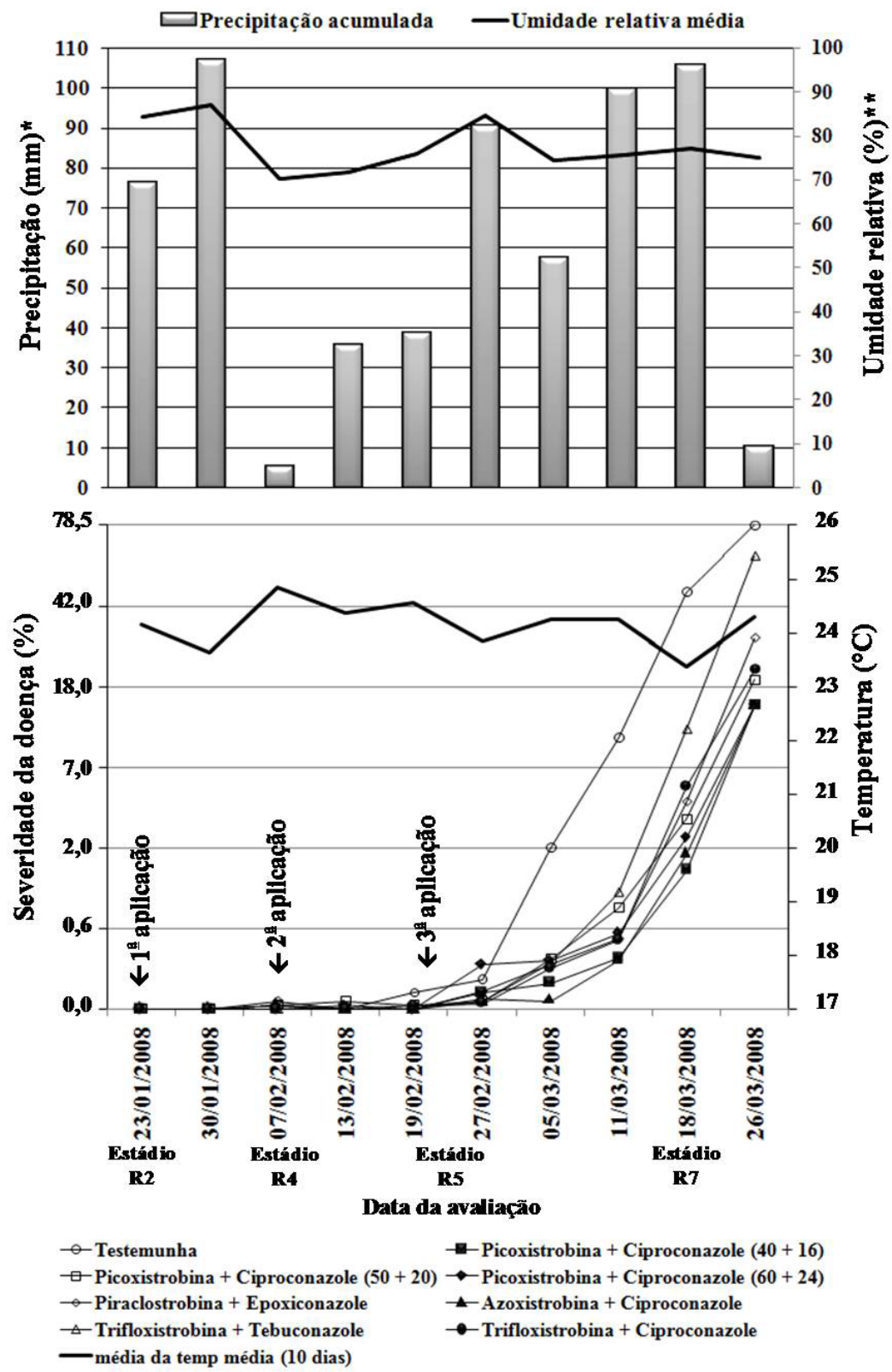

Fig. 3 - Curva de progresso da severidade da ferrugem asiática, Phakopsora pachyrhizi, no terço superior de plantas de soja cultivar BRS 256 RR submetidas ou não às aplicações de fungicidas e a relação com as condições climáticas. Campo Grande, MS, 2007-2008. Acúmulo (*) e média (**) de 10 dias priori a data da avaliação da doença. Valores entre parênteses na legenda correspondem à dose do produto (g i.a./ha).

De acordo com os valores de AACPD, trifloxistrobina + tebuconazole foi o fungicida menos eficiente para o controle de P. pachyrhizi no terço inferior da soja, embora tenha sido superior à testemunha (Tabela 1). As plantas submetidas aos demais fungicidas apresentaram AACPDI reduzida em 27,0 (picoxistrobina + epoxiconazole) a 36,0\% (picoxistrobina + ciproconazole- $60+24$ gi.a/ha), quando comparadas às plantas não tratadas. Apesar desses fungicidas não se diferenciarem entre si, em termos absolutos, os menores índices de AACPDI foram alcançados com aplicações de picoxistrobina + ciproconazole, especialmente quando se utilizou a maior dose (Tabela 1).
Como pressuposto, houve atraso no desenvolvimento da doença no terço superior das plantas, em comparação ao terço inferior (Fig. 3). A radiação solar direta constitui uma das causas deste atraso, pois, além dos esporos de P. pachyrhizi serem sensíveis aos raios UV (Del PonTE; AlvEs, 2009), ocorre diminuição do tempo de molhamento foliar, desfavorecendo o processo de infecção. Outros fatores podem estar relacionados, como o melhor estado fisiológico das folhas superiores (mais novas) em relação às folhas baixeiras e, no caso das plantas tratadas, a influência da distribuição da pulverização, que tem maior deposição na parte superior do dossel. 
Tabela 1 - Áreas abaixo da curva de progresso da ferrugem asiática, Phakopsora pachyrhizi, nos terços inferior (AACPDI) e superior (AACPDS) das plantas e da desfolha (AACPDes) no cultivar de soja BRS 256 RR. Campo Grande, MS, 2007-2008.

\begin{tabular}{lccc}
\hline Tratamentos & AACPDI & AACPDS & AACPDes \\
\hline Testemunha & $91,2^{*} \mathrm{a}$ & $56,2 \mathrm{a}$ & $1312,5 \mathrm{a}$ \\
Picoxistrobina + Ciproconazole $(40+16)^{\varphi}$ & $60,2 \mathrm{c}$ & $31,0 \mathrm{~b}$ & $972,1 \mathrm{bcd}$ \\
Picoxistrobina + Ciproconazole $(50+20)$ & $61,2 \mathrm{c}$ & $37,9 \mathrm{~b}$ & $909,1 \mathrm{~cd}$ \\
Picoxistrobina + Ciproconazole $(60+24)$ & $58,5 \mathrm{c}$ & $36,9 \mathrm{~b}$ & $842,6 \mathrm{~d}$ \\
Piraclostrobina + Epoxiconazole & $66,4 \mathrm{c}$ & $37,4 \mathrm{~b}$ & $994,9 \mathrm{bcd}$ \\
Azoxistrobina + Ciproconazole & $65,1 \mathrm{c}$ & $29,6 \mathrm{~b}$ & $987,0 \mathrm{bcd}$ \\
Trifloxistrobina + Tebuconazole & $78,2 \mathrm{~b}$ & $39,9 \mathrm{~b}$ & $1155,0 \mathrm{ab}$ \\
Trifloxistrobina + Ciproconazole & $63,0 \mathrm{c}$ & $35,0 \mathrm{~b}$ & $1054,4 \mathrm{bc}$ \\
\hline CV $(\%)$ & 7,6 & 18,1 & 12,4
\end{tabular}

${ }^{*}$ Médias seguidas pela mesma letra na coluna não diferem entre si pelo teste de Duncan no nível de $5 \%$ de probabilidade. ${ }^{\varphi}$ Valores entre parênteses correspondem à dose do produto (g i.a./ha).

Tabela 2 - Rendimento de grãos (Rend, em kg/ha), massa de 1.000 grãos (MMG, em g) e ganhos de rendimento (Grend, em \%) e de massa de 1.000 grãos (Gmmg, em \%) obtidos nos diferentes tratamentos para o controle da ferrugem asiática, Phakopsora packyrhizi, no cultivar de soja BRS 256 RR. Campo Grande, MS, 2007-2008.

\begin{tabular}{lcccc}
\hline Tratamentos & Rend & Grend* & MMG & Gmmg** \\
\hline Testemunha & $1997,9{ }^{\circ} \mathrm{c}$ & - & $108,3 \mathrm{~d}$ & - \\
Picoxistrobina + Ciproconazole $(40+16)^{\varphi}$ & $3011,3 \mathrm{ab}$ & 50,7 & $133,7 \mathrm{~b}$ & 23,5 \\
Picoxistrobina + Ciproconazole $(50+20)$ & $2839,4 \mathrm{ab}$ & 42,1 & $133,6 \mathrm{bc}$ & 23,4 \\
Picoxistrobina + Ciproconazole $(60+24)$ & $3179,8 \mathrm{a}$ & 59,2 & $133,4 \mathrm{bc}$ & 23,3 \\
Piraclostrobina + Epoxiconazole & $2748,3 \mathrm{ab}$ & 37,6 & $143,2 \mathrm{ab}$ & 32,3 \\
Azoxistrobina + Ciproconazole & $3050,3 \mathrm{ab}$ & 52,7 & $147,2 \mathrm{a}$ & 35,9 \\
Trifloxistrobina + Tebuconazole & $2602,6 \mathrm{~b}$ & 30,3 & $128,2 \mathrm{c}$ & 18,4 \\
Trifloxistrobina + Ciproconazole & $3061,6 \mathrm{ab}$ & 53,2 & $143,6 \mathrm{ab}$ & 32,6 \\
\hline CV\% $\%$ & 10,3 & & 4,2 &
\end{tabular}

*Ganho (\%) de Rend em relação à testemunha. ${ }^{* *}$ Ganho (\%) de MMG em relação à testemunha. ${ }^{\rho}$ Médias seguidas pela mesma letra na coluna não diferem entre si pelo teste de Duncan no nível de $5 \%$ de probabilidade. ${ }^{\varphi}$ Valores entre parênteses correspondem à dose do produto (g i.a./ha).

A severidade da ferrugem asiática foi maior no terço superior quando as folhas baixeiras apresentaram maior intensidade da doença (Figs. 2 e 3). Com a produção abundante de inóculo nas folhas baixeiras eas condições climáticas favoráveis ocorreu a dispersão do patógeno para as folhas superiores e o rápido aumento dos níveis de $P$. pachyrhizi. No intervalo de 13 dias (27/2 a 11/3/2008) a severidade da doença no terço superior das plantas não tratadas que era inferior a $0,6 \%$ passou para cerca de $13,0 \%$ (Fig. 3). A severidade da ferrugem asiática nas plantas tratadas permaneceu abaixo de $0,6 \%$ até a primeira semana do mês de março. Contudo, a partir de $11 / 3 / 2008$, foi constatado aumento acentuado da taxa de desenvolvimento da epidemia nessas plantas, sobretudo no tratamento envolvendo trifloxistrobina + tebuconazole (Fig. 3). Tal mudança de padrão das curvas de progresso da doença coincide com àquela observada no terço inferior das plantas, atribuída à redução/término da ação fungicida e/ou à precipitação acumulada do período.
A análise da AACPD para o terço superior da soja indicou que não houve diferenças entre os fungicidas quanto à redução dos níveis de ferrugem asiática, embora tenham superado o tratamento testemunha (Tabela 1). Tal resultado, provavelmente, foi decorrência das condições menos favoráveis encontradas pelo patógeno nessa região da planta.

Analisando-se as variáveis climáticas, constatouse que, a partir do surgimento da doença no campo até o final do ensaio, a temperatura média permaneceu entre 23 e $25^{\circ} \mathrm{C}$ (Figs. 2 e 3), enquadrando-se na faixa considerada adequada à $P$. pachyrhizi $\left(18 \mathrm{a} 26^{\circ} \mathrm{C}\right)$ pelo Mapa (2008). Para Alves et al. (2006), a faixa ótima de temperatura para a germinação do patógeno é de 15 a $25^{\circ} \mathrm{C}$. As precipitações também foram expressivas, possibilitando a manutenção delongos períodos com alta umidade relativa (UR) e, consequentemente, a evolução da epidemia da ferrugem asiática (Figs. 2 e 3). No geral, os eventos de precipitação contribuíram para o aumento da severidade da ferrugem asiática, o que corroborou com as observações de Del PONTE 
et al. (2006). Considerando o período entre a detecção dos primeiros sintomas (30/1/2008) e o momento em que se atingiu a severidade máxima (18/3/2008) no terço inferior das plantas não tratadas, constatou-se alta correlação positiva $(\mathrm{r}=0,86 ; \mathrm{P}=0,01)$ entre os valores de precipitação acumulada e a severidade de P. pachyrhizi. Para o terço superior dessas plantas, também foi observado alto coeficiente de correlação entre a precipitação acumulada e a severidade da doença $(r=0,74, P=0,01)$. Segundo Tschanz (1982), o efeito direto da chuva sobre a epidemia pode estar relacionado com a dispersão dos esporos dentro do dossel. Além disso, a chuva promove o molhamento foliar necessário para o início da infecção. Em contrapartida, não se evidenciou correlação significativa entre a severidade da doença e a UR. Os índices de umidade relativa do ar durante o período das avaliações se mantiveram altos (acima de $70 \%$ ), com pequenas variações, favorecendo ao desenvolvimento do patógeno. Tais condições, típicas para a região em estudo, comprometeram a análise do efeito da UR sobre a epidemia da ferrugem asiática.

A Figura 4 ilustra a evolução da desfolha no terço inferior das plantas submetidas aos diferentes tratamentos. Logo na primeira avaliação (18/3/2008), constatou-se $75,0 \%$ de desfolha nas plantas não tratadas (Fig. 4). Essa abscisão foliar precoce ocorreu em função do coalescimento das lesões causadas pelo patógeno, devido à elevada severidade (78,5\%) (Fig. 2). A partir da segunda avaliação, as plantas não tratadas apresentaram o terço inferior completamente desfolhado.

Como esperado, o efeito negativo dos fungicidas sobre P. pachyrhizi, dificultando a formação de novas lesões, retardou a senescência e a desfolha das plantas. Na segunda avaliação, os índices de desfolha das plantas tratadas foram inferiores ao observado no tratamento testemunha $(100,0 \%)$, variando de 62,5 (picoxistrobina + ciproconazole $-60+24$ g i.a/ha) a 85,0\% (trifloxistrobina + ciproconazole). Exceção feita ao fungicida trifloxistrobina + tebuconazole, cujo índice de desfolha $(95,0 \%)$ foi próximo ao observado para as plantas não tratadas (Fig. 4). Em 2/4/2008, a desfolha acentuada atingiu todos os tratamentos, não havendo diferenças significativas entre eles (dados não apresentados). Com base na AACPDes, plantas submetidas às aplicações de picoxistrobina + ciproconazole, sobretudo a maior dose, apresentaram menor desfolha (Tabela 1). Em termos absolutos, os maiores índices de AACPDes foram atribuídos aos tratamentos testemunha, trifloxistrobina + tebuconazole e trifloxistrobina + ciproconazole.

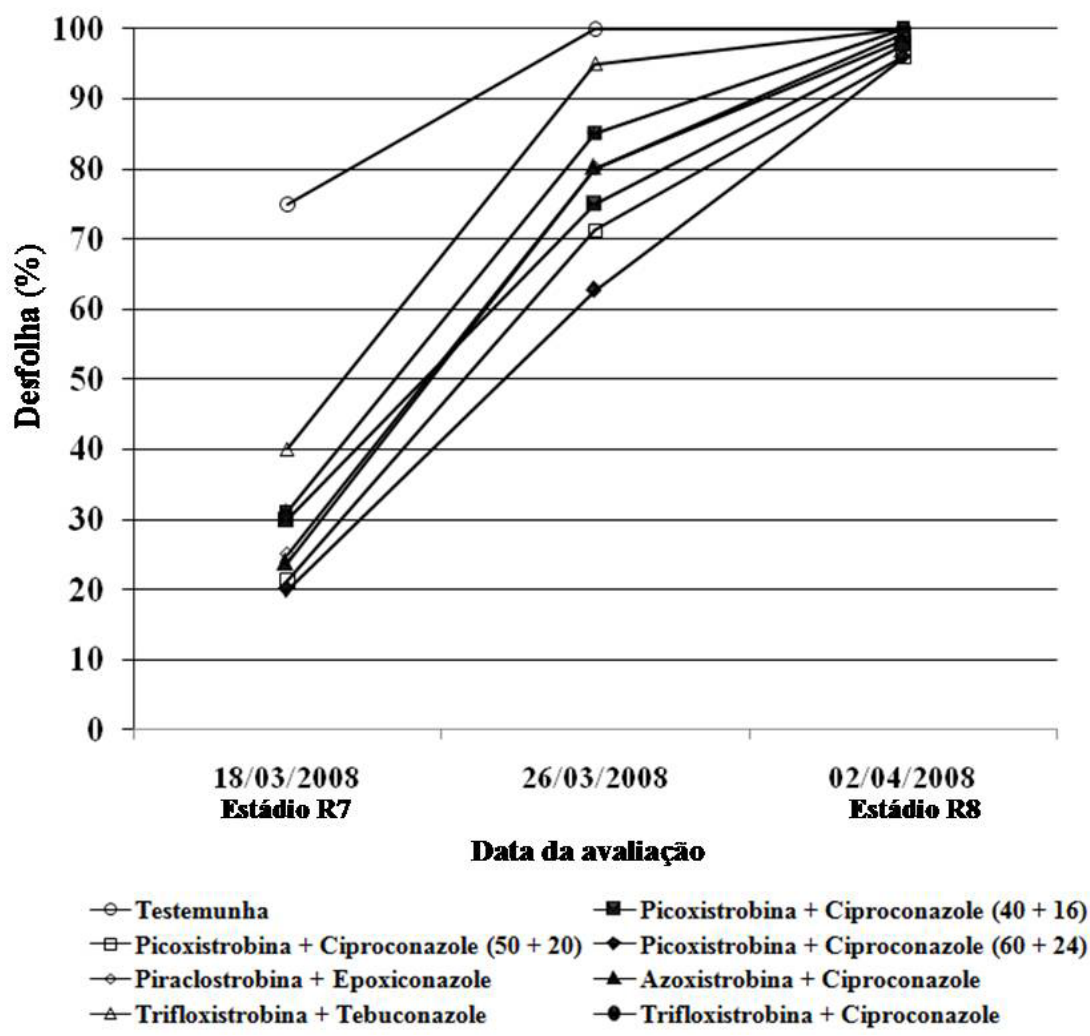

Fig. 4 - Curva de progresso da desfolha observada no terço inferior de plantas de soja cultivar BRS 256 RR submetidas aos diferentes tratamentos para o controle da ferrugem asiática (Phakopsora pachyrhizi). Campo Grande, MS, $2007-2008$. Valores entre parênteses na legenda correspondem à dose do produto (g i.a./ha). 
Tabela 3 - Rendimento de grãos (Rend, em kg/ha), ganho de rendimento (Grend, em kg/ha), custo da aplicação de fungicidas (Custo, em kg/ha), margem líquida (Mliq, em kg/ha e R\$), lucro líquido (Lliq, em R\$) e ganho em receita (Grec, em \%) nos diferentes tratamentos para o controle da ferrugem asiática, Phakopsora packyrhizi, no cultivar BRS 256 RR. Campo Grande, MS, 2007-2008.

\begin{tabular}{|c|c|c|c|c|c|c|c|}
\hline \multirow{2}{*}{ Tratamentos } & \multirow{2}{*}{ Rend $^{1}$} & \multirow{2}{*}{ Grend $^{2}$} & \multirow{2}{*}{ Custo $^{3}$} & \multicolumn{2}{|c|}{ Mliq $^{4}$} & \multirow{2}{*}{ Lliq $^{6}$} & \multirow{2}{*}{ Grec $^{7}$} \\
\hline & & & & $\mathrm{kg} / \mathrm{ha}$ & $\mathrm{R} \$^{5}$ & & \\
\hline Testemunha & 1997,9 & - & - & - & - & 303,1 & - \\
\hline Picoxistrobina + Ciproconazole $(40+16)^{\varphi}$ & 3011,3 & 1013,4 & 158,9 & 854,5 & 564,0 & 867,0 & 186,1 \\
\hline Picoxistrobina + Ciproconazole $(50+20)$ & 2839,4 & 841,5 & 188,4 & 653,1 & 431,1 & 734,1 & 142,2 \\
\hline Picoxistrobina + Ciproconazole $(60+24)$ & 3179,8 & 1181,9 & 218,0 & 963,9 & 636,2 & 939,3 & 209,9 \\
\hline Piraclostrobina + Epoxiconazole & 2748,3 & 750,4 & 206,6 & 543,8 & 358,9 & 662,0 & 118,4 \\
\hline Azoxistrobina + Ciproconazole & 3050,3 & 1052,4 & 188,0 & 864,4 & 570,5 & 873,6 & 188,2 \\
\hline Trifloxistrobina + Tebuconazole & 2602,6 & 604,7 & 252,1 & 352,6 & 232,7 & 535,8 & 76,8 \\
\hline Trifloxistrobina + Ciproconazole & 3061,6 & 1063,7 & 177,1 & 886,6 & 585,2 & 888,2 & 193,1 \\
\hline
\end{tabular}

${ }^{1}$ Rendimento de grãos (kg/ha).

${ }^{2} \mathrm{Ganho}(\mathrm{kg} / \mathrm{ha})$ em relação à testemunha.

${ }^{3}$ Custo de três aplicações de fungicida $(\mathrm{kg} / \mathrm{ha})$.

${ }^{4}$ Margem líquida: acréscimo promovido pela aplicação de fungicidas.

${ }^{5} \mathrm{~kg}$ de soja = R\$0,66 (cotação em 25/4/2008, Campo Grande, MS), com FOB e ICMS excluso (SIMA/CEASA, 2008).

${ }^{6}$ Lucro líquido (R\$): valor da produção descontados os custos de produção, o qual na ausência de controle da ferrugem asiática correspondeu à R\$1.015,56/ha, na safra 2007-2008 ((RicheTTI, 2007).

${ }^{7}$ Ganho em receita (\%) em relação à testemunha.

jValores entre parênteses correspondem à dose do produto (g i.a./ha).

A produtividade da soja, expressa em rendimento ( $\mathrm{kg} / \mathrm{ha}$ ) e massa de 1.000 grãos (g), foi reduzida em função da intensidade de $P$. pachyrhizi (Tabelas 1 e 2). Altos coeficientes de correlação negativa foram observados quando os valores de AACPDI foram confrontados com os índices de rendimento $(\mathrm{r}=-0,94$, $\mathrm{P}=0,01)$ e massa de 1.000 grãos $(\mathrm{r}=-0,78, \mathrm{P}=0,02)$. Os valores de AACPDS também foram correlacionados negativamente com o rendimento $(r=-0,91$, $\mathrm{P}=0,01)$ e massa de 1.000 grãos $(\mathrm{r}=-0,89, \mathrm{P}=0,01)$. Por fim, constatou-se decréscimo de rendimento $(\mathrm{r}=-0,87, \mathrm{P}=0,01)$ e de massa de 1000 grãos $(\mathrm{r}=-0,67$, $\mathrm{P}=0,07)$ com o aumento da desfolha (AACPDes). Esses resultados estão de acordo com NAVARINI et al. (2007) e BARRos et al. (2008), os quais admitiram existir correlação negativa significativa entre os níveis de severidade de P. pachyrhizi e a produtividade da soja.

A aplicação dos fungicidas promoveu ganhos em rendimento de grãos $(\mathrm{kg} / \mathrm{ha})$, os quais variaram de aproximadamente 30,0 (trifloxistrobina + tebuconazole) a 59,0\% (picoxistrobina + ciproconazole - 60 + 24 g i.a/ha) em relação à testemunha (Tabela 2). O rendimento médio das plantas tratadas foi de aproximadamente $46,5 \%$ superior ao constatado para as plantas não tratadas. Esse percentual foi semelhante ao obtido por Costamilan et al. (2002). Em termos absolutos, o maior e o menor índice de rendimento foram atribuídos ao fungicida picoxistrobina + ciproconazole $(60+24$ g i.a./ha) e trifloxistrobina + tebuconazole, respectivamente. Da mesma forma, todos os fungicidas garantiram valores de massa de
1.000 grãos superiores ao observado para as plantas não tratadas (Tabela 2). Para essa variável, as aplicações de azoxistrobina + ciproconazole promoveram o maior índice de massa de 1000 grãos (147,2 g), embora não tenha se destacado de piraclostrobina + epoxiconazole $(143,2 \mathrm{~g})$ e trifloxistrobina + ciproconazole $(143,6 \mathrm{~g})$. Em contrapartida, o fungicida que promove menor ganho de massa de 1.000 grãos $(18,4 \%)$ foi trifloxistrobina + tebuconazole $(128,2 \mathrm{~g})$. No presente ensaio, a diferença de massa de 1.000 grãos média das plantas tratadas e não tratadas foi de 27,0\%. Para a mesma variável, Costamilan et al. (2002) obtiveram diferença de 22,0\% entre plantas com e sem aplicação de fungicidas

Mesmo na ausência de controle da ferrugem asiática, o cultivo da soja promoveu lucro líquido (Tabela 3). Contudo, a aplicação dos fungicidas gerou receita superior $(77,0$ a $210,0 \%)$ em relação à testemunha. Notou-se diferença significativa de produtividade entre as plantas submetidas aos fungicidas e à testemunha, evidenciando a importância do controle da ferrugem asiática da soja. Embora tenha apresentado o segundo maior custo de aplicação, o emprego da maior dose de picoxistrobina + ciproconazole resultou no maior lucro líquido, reflexo da maior eficiência do controle da ferrugem asiática e, por consequente, a manutenção do rendimento de grãos. Em contrapartida, aplicações de trifloxistrobina + tebuconazole promoveram o menor lucro líquido, como resultado da menor eficiência de controle da doença (Tabela 3). 


\section{CONCLUSÕES}

Para as condições de Campo Grandes, MS, com base na severidade da doença, rendimento de grãos e nos benefícios econômicos, os fungicidas mais promissores para o controle de $P$. packyrhizi são picoxistrobina + ciproconazole $(60+24$ g i.a./ha), azoxistrobina + ciproconazole e trifloxistrobina + ciproconazole.

\section{REFERÊNCIAS}

ALVES, A.M.; FURTADO, G.Q.; BERGAMIN, A. Influência das condições climáticas sobre a ferrugem da soja. In: ZAMBOLIM, L. Manejo integrado: ferrugem da soja e doenças quarentenárias do citros. Viçosa: Suprema, 2006. p.37-59.

AZEVEDO, L.A.S. de Proteção integrada de plantas com fungicidas: teoria, prática e manejo. São Paulo, 2001. 230p.

BARROS, H.B.; SEDIYAMA, T; REIS, M.S.; CECON, P.R. Efeito do número de aplicações de fungicidas no controle da ferrugem asiática da soja. Acta Scientiarum Agronomy, v.30, n.2, p.239-245, 2008.

BRAZIL. Ministério da Agricultura, pecuária e abastecimento. Consorcio antiferrugem asiática da soja. 2007/2008. Disponível em: <http://www.consorcioantiferrugem. net>. Acesso em: 31 mar. 2008.

COSTAMILAN, L.M.; BERTAGNOLLI, P.F.; YORINORI, J.T. Avaliação de danos em soja causados por ferrugem asiática. Passo Fundo: Embrapa Trigo, 2002. (Comunicado Técnico, n. 96).

DEL PONTE, E.M.; ALVES, R.C. Ferrugem asiática da soja. In: DEL PONTE, E.M. (Ed.). Fitopatologia.net: herbário virtual. Departamento de Fitossanidade. Agronomia, UFRGS. Disponível em: <http:/ / www.ufrgs.br/ agronomia/fitossan/fitopatologia/ficha.php?id=143>. Acesso em: 12 mar 2009.

DEL PONTE, E.M.; GODOY, C.V.; LI, X.; YANG, X.B. Predicting severity of Asian Soybean rust epidemics with empirical rainfall models. Phytopathology, v.96, n.7, p.797-803, 2006.

FURLAN, S.H. Impacto, diagnose e manejo da ferrugem asiática da soja no Brasil. In: REUNIÂO ITINERANTE DE FITOSSANIDADE DO INSTITUTO BIOLÓGICO, 11., 2005, Aguaí. Anais. Aguaí, 2005. (CD-ROM).

GODOY, C.V.; COSTAMILAN, L.M.; CANTERI, M.G.; ALMEIDA, A.M.R.; PIUGA, F.F. Análise temporal do progresso da ferrugem da soja em Londrina (PR). In: CONGRESSO BRASILEIRO DE FITOPATOLOGIA, 36. , 2003, Uberlândia. Anais. Uberlândia: UFU, 2003. p.386.
GODOY, C.V.; KOGA, L.J.; CANTERI, M.G. Diagramatic scale for assessment of soybean rust severity. Fitopatologia Brasileira, v.31, p.63-68, 2006.

HOFFMANN, R.; ENGLER, J.J. de C.; SERRANO, O.; THAME, A.C. de M.; NEVES, E.M. Administração da empresa agrícola. São Paulo: Pioneira, 1984. 325p.

IBGE. Instituto Brasileiro de Geografia e Estatística. Disponível em: <http://www.ibge.gov.br/home/>. Acesso em: 29 mar. 2009.

MORI, C. de; COSTAMILAN, L.M. Ferrugem da soja: Estimativas de custo de controle, em Passo Fundo, RS. Passo Fundo: Embrapa Trigo, 2004. 10p. (Documentos Online, 32). Disponível em: <http://www.cnpt.embrapa.br/ biblio/ do/p_do32.htm>. Acesso em: 29 mar. 2009.

NAVARINI, L.; DALLAGNOL, L.J.; BALARDIN, R.S.; MOREIRA, M.T.; MENEGHETTI, R.C.; MADALOSSO, M.G. Controle químico da ferrugem asiática (Phakopsora packyrhizi Sidow) na cultura da soja. Summa Phytopathologica, v.33, n.2, p.182-186, 2007.

REIS, E.F. dos; LIMA NETO, V. da C.; GODOY, C.V.; ROSA, C.T.; CASTANHO, H.E.; VICENTE, N.G. Controle químico da ferrugem asiática da soja na região sul do Paraná. Scientia Agrária, v.8, n.3, p.319-323, 2007.

RICHETTI, A. Estimativa de custo de produção de soja, safra 2007/08, para Mato Grosso do Sul e Mato Grosso. Dourados: Embrapa Agropecuária Oeste, 2007. 11p. (Comunicado Técnico, n. 134).

SAS INSTITUTE. SAS/STAT software: changes and enhancements through release 9.1. Cary, NC, 2003. 5136p.

\section{CENTRAIS DE ABASTECIMENTO DE MATO GROS-} SO DO SUL. - CEASA/MS. Campo Grande, MS: SIMA/ CEASA. Disponível em: <http://www.ceasa.ms.gov. br>. Acesso em: 26 abr. 2008.

SINCLAIR, J.F.; HARTMAN, G.L. Soybean rust. In: HARTMAN, G.L; SINCLAIR, J.F.; RUPE, J.C. (Ed.). Compendium of soybean diseases. 4.ed. St. Paul: APS, 1999. p.3-4.

SOARES R.M; RUBIN S.A.L; WIELEWICKI A.P; OZELAME J.G. Fungicidas no controle da ferrugem asiática (Phakopsora pachyrhizi) e produtividade da soja. Ciência Rural, v.34, p.1245-1247, 2004.

TSCHANZ, A.T. Soybean rust epidemiology: final report. Shanhau: Asian Vegetable Research and Development Center, 1982. 157p.

WHITE, N.; CHAKRABORTY, S.; FERNANDES, C.D.; CHARCHAR, M.J.; MELKANIA, N.P.; RAMESH, C.R.; GANGAIAH, L.; GUODAO, L.; CAMERON, D.F.; MILES, J. Selection of high yielding and anthracnose resistant Stylosanthes for Brazil, India and China. In: INTERNATIONAL GRASSLAND CONGRESS, 19., 2001, São Pedro. Proceedings. São Pedro, 2001. p.234-236. 
YORINORI, J. T. Ferrugem Asiática avança e exige cuidados mais intensos. Correio Agrícola, v.1, p.3-6, 2007.

YORINORI, J.T.; PAIVA, W.M.; FREDERICK, R.D.; FERNANDEZ, P.F.T. Ferrugem da soja (Phakopsora pachyrhizi) no Brasil e no Paraguai, nas safras 2000/01 e
2001/02. In: CONGRESSO BRASILEIRO DE SOJA, 2., 2002, Foz do Iguaçu. Resumos. Foz do Iguaçu, 2002. p.94.

Recebido em $4 / 5 / 10$

Aceito em 31/1/11 